\title{
A comparison of hysterosalpingography and laparoscopy in the evaluation of tubal factors in female infertility
}

\author{
Ankita Gupta*, Purnima Upreti \\ Department of Obstetrics and Gynecology, HIMS, SRHU, Dehradun, Uttarakhand, India \\ Received: 23 April 2020 \\ Accepted: 12 June 2020 \\ *Correspondence: \\ Dr. Ankita Gupta, \\ E-mail: anks118@gmail.com \\ Copyright: () the author(s), publisher and licensee Medip Academy. This is an open-access article distributed under \\ the terms of the Creative Commons Attribution Non-Commercial License, which permits unrestricted non-commercial \\ use, distribution, and reproduction in any medium, provided the original work is properly cited.
}

\begin{abstract}
Background: WHO defines infertility as "failure to conceive after having regular, unprotected intercourse for one year. Factors responsible - male factors (20-30\%), female factors (40-55\%), combined male and female factors (10$40 \%$ ) and unexplained infertility (10-20\%). Amongst female factors, tubal factors are responsible for 25-30\% of infertility. Hysterosalpingography and diagnostic laparoscopy with chromopertubation are widely used in the evaluation of tubal factors of infertility. The aim of this study was to compare findings of HSG and diagnostic laparoscopy with chromopertubation for tubal patency in infertile women.

Methods: An observational study, done on a total of 125 females suffering from primary and secondary infertility who underwent HSG and then 97 patients who gave consent, underwent diagnostic laparoscopy with chromopertubation. The data was entered in MS excel spreadsheet and analysis was done using statistical package for social sciences (SPSS) version 21.0.

Results: Primary infertility cases were more than secondary infertility cases. Mean age of patients was found to be $28.92 \pm 5.33$ years. Most common tubal abnormality found on hysterosalpingography and chromopertubation was bilateral tubal block. Inter rater kappa agreement used and significant agreement found between hysterosalpingography and chromopertubation with kappa value of 0.612 .

Conclusions: From this study authors conclude that HSG and laparoscopy with chromopertubation are complimentary to each other. Laparoscopy helps in identification of tubal and non-tubal factors like intra-abdominal and pelvic adhesions, endometriosis etc. and simultaneously they can be treated while HSG helps in evaluation of tubal factors as well as of intra-uterine factors like synechiae, polyps etc.
\end{abstract}

Keywords: Chromopertubation, Diagnostic laparoscopy, Hysterosalpingography, Infertility

\section{INTRODUCTION}

WHO defines infertility as "failure to conceive after having regular, unprotected intercourse for one year". Infertility is of two types, primary: where conception has never taken place and secondary: where prior conception has occurred irrespective of the outcome of pregnancy. ${ }^{2}$ As per systemic analysis and National Heath Surveys conducted in the year 2010, approximately $2 \%$ women suffered from primary infertility and approximately $10.5 \%$ from secondary infertility. ${ }^{3}$ The major factors responsible for infertility can be categorised as "male factors $(20-30 \%)$, female factors (40-55\%), combined male and female factors $(10-40 \%)$ and unexplained infertility (10-20\%).

Amongst female factors, tubal factors are responsible for 25-30\% of infertility. ${ }^{4}$ Nowadays hysterosalpingography (HSG) and diagnostic laparoscopy along with chromopertubation (CPT) are widely used in the evaluation of tubal factors of infertility. The purpose of this study was to compare findings of "HSG and diagnostic laparoscopy with chromopertubation in the evaluation of tubal factors "in infertile women. 


\section{METHODS}

The study was conducted in the department of obstetrics and gynecology, Himalayan Institute of Medical Sciences (HIMS), Swami Ram Nagar, Dehradun, over a period of 12 months from August 2017 to July 2018. Subjects were recruited from amongst the patients who came to gynecology OPD with primary or secondary infertility as per WHO criteria. A written informed consent was taken in Hindi and English from the subjects involved in the study. Ethical clearance was taken from the ethical committee of the university.

\section{Inclusion criteria}

- Cases of primary and secondary infertility with

- No ovulatory dysfunction

- Normal semen analysis and other parameters in male partner.

\section{Exclusion criteria}

- On-going or recent pelvic infection

- Late menstruation without confirmation of absence of pregnancy

- Technical problems resulting in an unsatisfactory HSG

- Any contraindication to diagnostic laparoscopy procedure like generalized peritonitis, intestinal obstruction, severe cardiopulmonary disease, anticoagulation therapy etc.

Women who attended gynecology OPD of Himalayan hospital during the study period and fulfilled the selection criteria were the subjects for study. A detailed history related to infertility and other relevant history was taken and recorded, including history of any previous treatment taken for infertility. The females were subjected to clinical examination which included general and systemic examination followed by local and gynaecological examination. After initial evaluation of the patient, HSG was done on day 8-11 of menstrual cycle on OPD basis followed by diagnostic laparoscopy with chromopertubation done on day 8-11 of menstrual cycle under general anaesthesia after 3 months of HSG and after ruling out pregnancy.

Demographic characteristic, findings of HSG and diagnostic laparoscopy with chromopertubation were recorded in a predesigned case recording form.

\section{Statistical analysis}

The data was entered in MS excel spreadsheet and analysis was done using statistical package for social sciences (SPSS) version 21.0. Variables were compared using independent t-test/Mann-Whitney test/Chi-square test where ever applicable.

\section{RESULTS}

Initially 125 patients fulfilling the criteria were recruited in the study, of which 28 patients were lost to follow up. Hence diagnostic laparoscopy with chromopertubation could be done in 97 patients only and the findings were then compared with HSG findings. Results as analysed on 97 patients were suggestive of - 65 patients were found to have primary infertility and 32 patients suffered from secondary infertility. The mean age of the patients in the study was found to be $28.92 \pm 5.33$ years with majority of patients belonging to the age group of 21-30 years. Mean age for cases of primary infertility was $28.4 \pm 5.05$ years and for secondary infertility was $29.97 \pm 5.81$ years $($ Table 1$)$.

Table 1: Age wise distribution of cases of primary and secondary infertility.

\begin{tabular}{|c|c|c|c|c|}
\hline \multirow{2}{*}{ Age distribution in years } & \multicolumn{2}{|l|}{ Type of infertility } & \multirow{2}{*}{ Total } & \multirow{2}{*}{ p value } \\
\hline & Primary infertility $(n=65)$ & Secondary infertility $(n=32)$ & & \\
\hline$<=20$ & $2(3.08 \%)$ & $1(3.13 \%)$ & $3(3.09 \%)$ & \multirow{7}{*}{0.762} \\
\hline $21-25$ & $22(33.85 \%)$ & $8(25.00 \%)$ & $30(30.93 \%)$ & \\
\hline $26-30$ & $20(30.77 \%)$ & $10(31.25 \%)$ & $30(30.93 \%)$ & \\
\hline $31-35$ & $16(24.62 \%)$ & $8(25.00 \%)$ & $24(24.74 \%)$ & \\
\hline$>35$ & $5(7.69 \%)$ & $5(15.63 \%)$ & $10(10.31 \%)$ & \\
\hline Mean \pm SD & $28.4 \pm 5.05$ & $29.97 \pm 5.81$ & $28.92 \pm 5.33$ & \\
\hline Median (IQR) & $28(24.750-33)$ & $29.5(25-34)$ & $28(25-33.250)$ & \\
\hline
\end{tabular}

The mean duration of infertility in primary infertility was $4.95 \pm 3.1$ years and in secondary infertility was $3.86 \pm 2.9$ years. Maximum number of patients suffered from infertility for one to three years (Table 2).

On HSG tubal blockage was found to be most common pathology. Bilateral tubal spill was found in 38 cases, bilateral tubal block was found in 38 cases, left tubal block was found in 9 cases and right tubal block was found in 12 cases. Other tubal pathologies detected on HSG were hydrosalpinx, tortuous tube and stricture found in one case each. One case had history of salpingectomy. Uterine pathology which could be commented upon HSG were synechiae, as found in four cases and arcuate uterus 
and bicornuate uterus found in two cases each. Infantile uterus, septum, abnormal uterine cavity shape and rudimentary horn was found in one case each.

On diagnostic laparoscopy with chromopertubation tubal blockage was the most common pathology found. Bilateral tubal spill was found in 54 cases, bilateral tubal block was found in 24 cases, left tubal block was found in 9 cases and right tubal block was found in 10 cases. Other tubal pathology detected on laparoscopy were hydrosalpinx in 8 cases, delayed spill was found in four cases, two case had fimbrial cyst and one had dilated fimbrial end. Abnormal tubal appearance like beaded appearance in three cases, sacculated appearance in one case, tortuous tubes in two cases and one patient had tubo-ovarian mass. Twenty-one patients had endometriosis. Eighteen patients had adhesions of which intra-peritoneal adhesion was found in eleven cases, four cases had pelvic adhesions and two had flimsy peritubal adhesions. Uterine fibroid was found in eleven cases and infantile uterus and arcuate uterus was found in one case each. Seven cases had cystic looking ovaries, three had enlarged ovaries and three had dermoid cyst.

Table 2: Distribution of cases as per duration of infertility and type of infertility.

\begin{tabular}{|c|c|c|c|c|}
\hline \multirow{2}{*}{ Duration of infertility in years } & \multicolumn{2}{|c|}{ Type of infertility } & \multirow{2}{*}{ Total } & \multirow{2}{*}{ p value } \\
\hline & Primary infertility $(n=65)$ & Secondary infertility $(n=32)$ & & \\
\hline 1-3 years & $27(41.54 \%)$ & $20(62.50 \%)$ & $47(48.45 \%)$ & \multirow{6}{*}{0.206} \\
\hline 4-6 years & $22(33.85 \%)$ & $6(18.75 \%)$ & $28(28.87 \%)$ & \\
\hline $7-9$ years & $11(16.92 \%)$ & $4(12.50 \%)$ & $15(15.46 \%)$ & \\
\hline $10-12$ years & $2(3.08 \%)$ & $2(6.25 \%)$ & $4(4.12 \%)$ & \\
\hline $13-15$ years & $3(4.62 \%)$ & $0(0.00 \%)$ & $3(3.09 \%)$ & \\
\hline Total & $65(100.00 \%)$ & $32(100.00 \%)$ & $97(100.00 \%)$ & \\
\hline Mean \pm SD & $4.95 \pm 3.1$ & $3.86 \pm 2.9$ & $4.59 \pm 3.06$ & \multirow{2}{*}{0.039} \\
\hline Median (IQR) & $4(2.875-6.250)$ & $3(2-5)$ & $4(2.375-6)$ & \\
\hline
\end{tabular}

Table 3: Correlation between tubal findings on HSG and CPT.

\begin{tabular}{|c|c|c|c|c|c|c|c|}
\hline \multirow{2}{*}{ HSG } & \multicolumn{4}{|l|}{ CPT results } & \multirow{2}{*}{ Total } & \multirow{2}{*}{ p value } & \multirow{2}{*}{ Kappa } \\
\hline & Bilateral spill & Bilateral block & Left block & Right block & & & \\
\hline Bilateral spill & $38(39.18 \%)$ & $0(0.00 \%)$ & $0(0.00 \%)$ & $0(0.00 \%)$ & $38(39.18 \%)$ & \multirow{5}{*}{$<0.0001$} & \multirow{5}{*}{0.612} \\
\hline Bilateral block & $5(5.15 \%)$ & $24(24.74 \%)$ & $5(5.15 \%)$ & $4(4.12 \%)$ & $38(39.18 \%)$ & & \\
\hline Left block & $5(5.15 \%)$ & $0(0.00 \%)$ & $4(4.12 \%)$ & $0(0.00 \%)$ & $9(9.28 \%)$ & & \\
\hline Right block & $6(6.19 \%)$ & $0(0.00 \%)$ & $0(0.00 \%)$ & $6(6.19 \%)$ & $12(12.37 \%)$ & & \\
\hline Total & $54(55.67 \%)$ & $24(24.74 \%)$ & $9(9.28 \%)$ & $10(10.31 \%)$ & $97(100.00 \%)$ & & \\
\hline
\end{tabular}

Inter rater kappa agreement was used and good significant agreement was found between HSG and CPT results with kappa value $0.612 .74 .23 \%$ of the findings of HSG were in agreement with CPT results. $39.18 \%$ of patients were found to have bilateral spill $(\mathrm{B} / \mathrm{L})$ in both HSG and CPT. $24.74 \%$ of patients had bilateral block according to both HSG and CPT findings. $4.12 \%$ left block and $6.10 \%$ right block were seen in both HSG and CPT findings $(\mathrm{p}<0.05)$. Out of 54 patients classified as $\mathrm{B} / \mathrm{L}$ spill by CPT discrepancy was seen in the results of HSG and CPT in 16 patients. 5 patients were classified as B/L block and left block each and 6 patients were classified as right block by HSG. No discrepancies were seen in the classification of B/L block by CPT and HSG.

All the patients who were classified as B/L block by CPT were also classified as B/L block by HSG. Out of 9 patients classified as left block by CPT only 4 were classified as left block and 5 were classified as B/L block by HSG. Out of 10 patients classified as right block by CPT majority of the patients were classified as right block and 4 patients were classified as B/L block (Table 3). Considering laparoscopy as gold standard, diagnostic test was used and sensitivity of HSG findings was found to be $69.01 \%$, specificity was found to be $46.15 \%$. $77.78 \%$ was the positive predictive value (PPV) of HSG and $35.29 \%$ was the negative predictive value (NPV). HSG had a diagnostic accuracy of $62.89 \%$.

\section{DISCUSSION}

Incidence of primary infertility was more than secondary infertility, similar results were found in studies conducted by Anuradha et al, and Saini et al. ${ }^{5,6}$ Age of the patients varied from 19-42 years with mean age being $28.92 \pm 5.33$ years and maximum patients belonged to the age group of 21-30 years and this was similar to studies conducted at Ahmedabad, Mysore, Nigeria. ${ }^{7,8}$ 
On HSG, 39.2\% had bilateral tubal patency and $21.6 \%$ had unilateral patency and the results were similar to one observed by Foroozanfard et al and Ben WJ Mol et al. ${ }^{9,10}$ On chromopertubation it was found that $55.67 \%$ (fifty four) of the patients had bilateral tubal spill, $24.74 \%$ (twenty four) of the patients had bilateral tubal block, $19.6 \%$ (nineteen) had unilateral tubal block $(10.31 \%$ of the patients had right block and $9.28 \%$ had left block) and similar results were observed in other studies also..$^{9,10}$

In this study bilateral tubal blockage was the most common tubal abnormality found on diagnostic laparoscopy. Apart from tubal blockage other laparoscopic findings of this study regarding the fallopian tubes were beaded and sacculated appearance of the fallopian tubes and tortuosity etc. Delayed spill on chromopertubation was found in $4.1 \%$ cases. Hydrosalpinx was found in $8.2 \%$ cases by laparoscopy. Even ovarian appearance could be commented upon by laparoscopy, like three patients had dermoid, enlarged and cystic ovaries were also found in some patients.

On laparoscopy, uterine causes of infertility accounted to only $8.8 \%$ cases of which congenital uterine anomaly was found in two patients one had infantile uterus and other had arcuate uterus. Uterine subserous leiomyomas were found in eleven patients $(11.3 \%)$ on laparoscopy. Other causes of infertility which were not found on HSG but were found on laparoscopy were endometriosis and adhesions. $21.7 \%$ cases had endometriosis and $18.6 \%$ had adhesions. Elaborating upon adhesions intraperitoneal adhesions were seen in eleven patients, pelvic adhesion was seen in four patients while peritubal adhesion was seen in only two patients and most of the adhesions were flimsy.

The additional findings observed by Geetha and Thilagavathy in their study apart from tubal blockage were peritubal adhesions in twenty-two cases, tuboovarian mass in two cases and hydrosalpinx in one and uterine findings observed were subserous fibroid in five cases, arcuate uterus in two and bicornuate uterus in one. Endometriosis was found in six cases. ${ }^{11}$

In a similar study conducted by Sachdeva and Kaur additional information obtained on laparoscopy was hydrosalpinx in three cases, delayed spill two cases and peritubal adhesions in three cases. Uterine factors that were observed were hypoplastic uterus in three cases, mullerian abnormalities in two cases and fibroid in two cases. Ovarian factors observed were PCOS in five cases, ovarian cyst and enlarged ovaries each in two cases and streak ovaries in one case. Peritoneal factors identified were endometriosis in three cases and pelvic adhesions in two cases. ${ }^{12}$

The superiority of laparoscopy over HSG has also been demonstrated by Sarkar et al as laparoscopy also helps in detection of ovarian, intra-abdominal and peritubal pathologies. $^{13}$

\section{CONCLUSION}

Hysterosalpingography is a useful tool in the initial work up of infertility especially in developing countries like India as it is cheap and relatively non-invasive and can be done on OPD basis and associated with minimal complications. It has its own limitations like it does not provide information about intra-peritoneal adhesions, endometriosis etc.

Laparoscopy provides a panoramic view of the pelvic cavity and peritoneal cavity thereby helping in the diagnosis of endometriosis, peritubal adhesions etc. there by bridging the gap between clinical examination and laparotomy and also helps in providing an opportunity for the treatment of the same. It has its own limitations like it is expensive and is associated with complications related to anaesthesia, pneumoperitoneum, visceral or vascular injuries.

From this study authors can conclude that HSG and laparoscopy are not alternative but complimentary to each other in evaluation of female infertility and the accuracy of diagnosing the tubal pathology for female infertility is increased when HSG and laparoscopy are used in conjunction.

\section{ACKNOWLEDGMENTS}

Authors would like to thank the Swami Rama Himalayan University for their support.

Funding: No funding sources

Conflict of interest: None declared

Ethical approval: The study was approved by the Institutional Ethics Committee of university

\section{REFERENCES}

1. World Health Organization. Sexual and reproductive health: Infertility definitions and terminology. Available

at: https://www.who.int/reproductivehealth/topics/inferti lity/en/. Accessed on $22^{\text {nd }}$ March 2020.

2. Rowe PJ, Comhaire FH, Hargreave TB, Mahmoud AM. WHO manual for the standardized investigation and diagnosis of the infertile male. Cambridge University Press; 2000.

3. Hodin S. The burden of infertility: global prevalence and women's voices from around the World. Maternal Health Task Force. 2017

4. Dutta DC. Text Book of Gynecology, $6^{\text {th }}$ edition, New Central Book Agency pvt Ltd. Chapter 10; 136137. Available at: http://bvhmch.in/wpcontent/uploads/2018/03/Gynaecology-DC-

Dutta.pdf. Accessed on $2^{\text {nd }}$ March 2020.

5. Anuradha J, Kumari KA, Sujatha A. Comparative study of tubal patency by hysterosalpingography, transvaginal sonosalpingography and laparoscopy. IAIM. 2016;3(9):126-33. 
6. Saini VK, Patel SC, Kawad K. Role of diagnostic laparoscopy in infertility-study of 50 cases. Int J Sci Res. 2013;2(7):290.

7. Adamson PC, Krupp K, Freeman AH, Klausner JD, Reingold AL, Madhivanan P. Prevalence and correlates of primary infertility among young women in Mysore, India. The Indian $\mathbf{J}$ Med Res. 2011;134(4):440.

8. Ibinaiye PO, Lawan RO, Avidime S. Comparative evaluation of pattern of abnormalities in hysterosalpingography, diagnostic laparoscopy and hysteroscopy among women with infertility in Zaria, Nigeria. Int J Med Med Sci. 2015;7(2):26-35.

9. Foroozanfard F, Sadat Z. Diagnostic value of hysterosalpingography and laparoscopy for tubal patency in infertile women. Nurs Midwifery Stud. 2013;2(2):188.

10. Oguntoyinbo AE. Department of radiology, faculty of clinical sciences college of health sciences, University of Ilorin, Ilorin, Nigeria, 2018. Available at: https://pdfs.semanticscholar.org/3c30/d440d75bee 9714fe34e99fc35354c56ed9ab.pdf. Accessed on $21^{\text {st }}$ March 2020

11. Geetha D, Thilagavathy D. Comparative evaluation of tubal patency by sterosalphingography and laparoscopic chromopertubation. J Den Med Sci. 2016;15(08):53-7.

12. Sachdeva PK, Kaur N. Role of hysterosalpingography and diagnostic laparoscopy in infertility. Int J Reprod Contracept Obstet Gynecol. 2016;5(11):3744.

13. Sakar MN, Gul T, Atay AE, Celik Y. Comparison of hysterosalpingography and laparoscopy in the evaluation of infertile women. Saudi Med J. 2008;29(9):1315-8.

Cite this article as: Gupta A, Upreti P. A comparison of hysterosalpingography and laparoscopy in the evaluation of tubal factors in female infertility. Int J Reprod Contracept Obstet Gynecol 2020;9:3047-51. 